\title{
PROCESSO DE FORMAÇÃO DAS ESTRATÉGIAS NO RESTAURANTE LEITE: UM ESTUDO ENTRE 1882 E 2009
}

\section{THE STRATEGY FORMULATION PROCESS IN THE "LEITE" RESTAURANT: A STUDY BETWEEN 1882 AND 2009}

\section{PROCESO DE FORMACIÓN DE LAS ESTRATEGIAS EN EL RESTAURANTE LEITE: UN ESTUDIO ENTRE 1882 Y 2009}

\section{Ana Rita de Melo Oliveira}

Pós-graduada em Gestão Financeira, auditoria e controladoria pela Fundação Getúlio Vargas - FGV Email: ritadeoliveira@gmail.com (Brasil)

\section{Eduardo de Aquino Lucena}

Doutor em Engenharia de Produção pela Universidade Federal de Santa Catarina - UFSC

Professor da Universidade Federal de Pernambuco - PROPAD/UFPE

Email: eaqlucena@yahoo.com.br (Brasil)

\section{Yákara Vasconcelos Pereira Leite}

Doutoranda do curso de Pós-Graduação em Administração da Universidade Federal de Pernambuco - UFPE

Professora da Universidade Federal Rural do Semi-Árido - UFERSA

Email: yakarav@gmail.com (Brasil)

\section{Viviane Santos Salazar}

Doutoranda do curso de Pós-Graduação em Administração da Universidade Federal de Pernambuco - UFPE

Professora e coordenadora do curso de Hotelaria da Universidade Federal de Pernambuco - UFPE Email: viviane_salazar@yahoo.com.br (Brasil) 
Processo de Formação das Estratégias no Restaurante Leite: Um Estudo entre 1882 e 2009

PROCESSO DE FORMAÇÃO DAS ESTRATÉGIAS NO RESTAURANTE LEITE: UM

ESTUDO ENTRE 1882 E 2009

\title{
RESUMO
}

O objetivo que motivou esta pesquisa foi o de investigar como ocorreu o processo de formação das estratégias do Restaurante Leite entre 1882 e 2009. Para alcançá-lo, utilizou-se uma abordagem teórica sobre o processo de formação de estratégias. Buscando descobrir as perspectivas dos respondentes, um estudo de caso qualitativo foi desenvolvido. Foram identificados eventos marcantes e oito fases. Observou-se que o processo de formação das estratégias ocorreu predominantemente pelo modo empreendedor e por estratégias deliberadas em sua maioria. Notouse ainda que, apesar do longo período de existência, a empresa adotou o modo empreendedor em toda a sua história.

Palavras-chave: Processo de Formação de Estratégias; Restaurantes; Restaurante Leite.

\section{THE STRATEGY FORMULATION PROCESS IN THE "LEITE" RESTAURANT: A STUDY BETWEEN 1882 AND 2009}

\begin{abstract}
The goal prompting this research was to investigate how the process of strategy formulation occurred in the "Leite" Restaurant between the years of 1882 and 2009. To do so, we used a theoretical approach for the strategy formulation process. We sought to discover the respondents' perspectives; hence, a qualitative case study was developed and identified eight key events and phases, having observed that the strategy formulation process occurred primarily through an entrepreneurial perspective with the use of deliberated strategies. Furthermore, despite the long period of existence, the company has adopted an entrepreneurial approach throughout its entire history.
\end{abstract}

Keywords: Strategy Formulation Process; Restaurants; Leite Restaurant.

Revista Ibero-Americana de Estratégia - RIAE, São Paulo, v. 9, n. 2, p. 25-50, mai./ago. 2010. 
PROCESO DE FORMACIÓN DE LAS ESTRATEGIAS EN EL RESTAURANTE LEITE: UN ESTUDIO ENTRE 1882 Y 2009

\section{RESUMEN}

El objetivo que motivó esta investigación fue estudiar cómo ocurrió el proceso de formación de las estrategias del Restaurante Leite entre 1882 y 2009. Para alcanzarlo, fue utilizado un enfoque teórico sobre el proceso de formación de estrategias. Buscando descubrir las perspectivas de los entrevistados, fue desarrollado un estudio de caso cualitativo. Fueron identificados eventos marcantes y ocho fases. Se observó que el proceso de formación de las estrategias ocurrió predominantemente por el modo emprendedor y principalmente por estrategias deliberadas. Se notó también que, a pesar del largo período de existencia, la empresa adoptó el modo emprendedor en toda su historia.

Palabras-clave: Proceso de Formación de Estrategias; Restaurantes; Restaurante Leche. 
Processo de Formação das Estratégias no Restaurante Leite: Um Estudo entre 1882 e 2009

\section{INTRODUÇÃO}

As empresas estão em constante tentativa de adaptação ao ambiente, seja por meio da implantação de uma nova tecnologia, pela criação de um produto, seja ainda por abertura ou fechamento de uma unidade negócios. O objetivo é a sobrevivência da organização em seu ambiente.

Em Administração, essas decisões representam as estratégias das empresas, sendo descritas, na maior parte dos livros-texto, como planos da alta administração para garantir resultados consistentes com as missões e objetivos da organização (MINTZBERG, AHLSTRAND, LAMPEL, 2000). No que se refere à estratégia como tema de estudo, o que despertou a curiosidade das autoras foi o processo pelo qual elas se formam. Como é o processo? Que forças influenciam? Ou seja, como ocorre o processo de formação de estratégias?

Apesar da popularidade do Planejamento Estratégico como a melhor forma de criar e implementar estratégias, Mintzberg (1998) argumenta que é um equívoco pensar que estas só se formam através de procedimentos deliberados, visto que também surgem de maneira não intencional. Por exemplo, quando as estratégias pretendidas não se realizam, dão espaço para o surgimento de estratégias emergentes.

Tendo em vista essa dicotomia, De Wit e Meyer (2004) explicam que se trata de um paradoxo no campo da administração estratégica. Além disso, os autores apontam a existência de certa demanda tanto para estratégias deliberadas como também para as emergentes. Com isso, a estratégia deliberada está mais voltada para o planejar, existindo a intencionalidade no processo.

Mintzberg (1978) ainda explica que as estratégias são padrões que se formam dentro de uma cronologia de acontecimentos e que sem essa perspectiva do passado fica inviável para o pesquisador entender o processo.

Nesse sentido, Idenburg (1993) afirma que estudos sobre estratégia parecem estar amadurecendo. Apesar do crescimento das publicações acadêmicas sobre estratégia, verifica-se que pesquisas voltadas à área de food service, especificamente dentro da temática de formação de estratégias, mostram-se tímidas, mesmo sendo um setor de representatividade econômica dentro da economia nacional. Food Service é uma atividade que consiste no serviço de alimentação fora do lar. Este segmento está voltado ao mercado transformador, ou seja, são estabelecimentos comerciais que transformam matéria-prima em pratos elaborados (Mahier, 2006).

Revista Ibero-Americana de Estratégia - RIAE, São Paulo, v. 9, n. 2, p. 25-50, mai./ago. 2010. 
Ana Rita de Melo Oliveira, Eduardo de Aquino Lucena, Yákara Vasconcelos Pereira Leite \& Viviane Santos Salazar

No caso de Pernambuco, o Estado se destaca pela qualidade de sua gastronomia, que é composta de uma variedade culinária, afirma Marcelo Brasil, ex-presidente da Associação Brasileira de Bares e Restaurantes de Pernambuco (ABRASEL, 2005). Dentre os restaurantes situados na cidade de Recife, o Leite é o mais antigo em funcionamento. Sua inaugurarão data de 1882 (Soares, 2000). Hoje o restaurante Leite é conhecido em diversas partes do mundo e tem ares de patrimônio histórico do Brasil, sendo mencionado nos guias de viagens de destaque no que se refere às atrações turísticas da cidade de Recife.

Em virtude da sua importância, acredita-se que a administração do Restaurante Leite requeira atenção, experiência e estudos, por visar à continuação de suas atividades. Isso manteria a sua atratividade turística da cidade, a arrecadação de impostos e os postos de trabalho. Além disso, pretendeu-se, com isso, também colaborar com a prática dos executivos atuais e futuros. Acreditase que, de posse dessas informações, os líderes organizacionais poderão realizar reflexões sobre o processo de formação das estratégias, auxiliando na administração para o alcance do desenvolvimento e da sobrevivência de seus negócios.

Tem-se, então, tanto a contribuição para a academia quanto para o campo da prática empresarial. Assim, as ações estratégicas do Restaurante Leite, que são referência para a gestão de restaurantes, devem ser analisadas para que teorias possam ser formuladas, servindo de diretrizes para diminuir o risco de futuros investimentos. Sendo assim, pela sua importância, o Leite foi escolhido como unidade foco do presente estudo, que tem o objetivo de investigar como ocorreu o processo de formação das estratégias do Restaurante Leite entre 1882 e 2009.

Para tanto, este trabalho está organizado em cinco seções. Além desta introdução, a segunda parte apresenta os conceitos que embasaram teoricamente o estudo. Em seguida, os procedimentos metodológicos são apresentados. Depois, os resultados são demonstrados com o apoio do marco teórico. Finalizando com a quinta seção que expõe as considerações finais.

\section{PROCESSO DE FORMAÇÃO DE ESTRATÉGIAS}

Precedendo a discussão sobre o processo de formação de estratégias, procurou-se esclarecer o conceito de estratégia. Pensou-se que, para analisar o fenômeno em investigação, seria importante obter essa definição.

Chandler (1998), Ansoff (1973) e Porter (1986) são autores que propõem uma abordagem prescritiva para as estratégias das empresas. Eles analisam aspectos das estratégias levando em

Revista Ibero-Americana de Estratégia - RIAE, São Paulo, v. 9, n. 2, p. 25-50, mai./ago. 2010. 
Processo de Formação das Estratégias no Restaurante Leite: Um Estudo entre 1882 e 2009

consideração a capacidade do estrategista de prever ações internas e externas à organização. Por pensarem que a maioria das estratégias é planejada, eles não reconhecem o seu surgimento tendendo a deixar o processo estratégico menos flexível.

Na opinião de Chandler (1998, p. 136), “estratégia é a definição dos principais objetivos em longo prazo de uma empresa, bem como a adoção de linhas de ação estratégica e a alocação de recursos tendo em vista esses objetivos". O autor acredita que as estratégias podem ser elaboradas a partir de um pensamento de antecipação de acontecimentos. Seguindo o pensamento de Chandler (1998), Henderson (1998, p. 5) complementa, ao explicar que estratégia é um plano de ação deliberado que se desenvolve e ajusta-se à vantagem competitiva de uma empresa. $\mathrm{O}$ autor ainda esclarece que se busca um processo interativo iniciado com o reconhecimento das capacidades organizacionais e dos objetivos pretendidos. Nessa perspectiva, a estratégia passou a ser reconhecida como um plano, um curso de ação conscientemente engendrado numa diretriz, possuindo duas características essenciais, a preparação prévia e o desenvolvimento consciente e deliberado (MINTZBERG, 2001, p. 27).

Para Grant (1995, p. 25-26), uma boa estratégia pode ser criada a partir de quatro ingredientes. O primeiro deles é o planejamento das metas de longo prazo; o segundo é o entendimento do ambiente externo; o terceiro é o conhecimento de suas capacidades e, por fim, tem-se a implementação. Segundo o autor, este último deve ocorrer com resolução, coordenação e comprometimento.

Já Porter (1999, p. 73) procurou explicar o seu significado no artigo “O que é estratégia?”. Acredita-se que uma das suas maiores contribuições nesse trabalho foi identificar a compatibilidade entre as atividades dentro das organizações gerando a vantagem competitiva. Ele definiu estratégia como a criação da sinergia entre as atividades da empresa, comentando, ainda, que o êxito da estratégia depende do bom desempenho de muitas atividades - e não apenas de umas poucas - e da integração entre elas.

As empresas buscam constantemente superar seus concorrentes e se manterem ativas no mercado. Porter (1991) afirma que para tanto é necessário a elaboração de estratégias, que são soluções únicas refletindo situações particulares. Entretanto, num sentido mais amplo, o autor encontra três estratégias genéricas que podem ser utilizadas para criar uma posição defensável a longo prazo e superar concorrentes em uma indústria. As três estratégias genéricas são: a de liderança no custo total, a de diferenciação e a do enfoque.

Não obstante, há autores que veem a noção de estratégia como algo não muito preciso, correspondendo à intangibilidade e a difícil visualização. Ohmae (1998 p.68-69), por exemplo,

Revista Ibero-Americana de Estratégia - RIAE, São Paulo, v. 9, n. 2, p. 25-50, mai./ago. 2010. 
afirma: "aquilo que os gerentes acreditam ser a estratégia, nada mais é do que a ponta do iceberg. Como o iceberg, a maior parte da estratégia está submersa escondida da visão”. Esse sentido põe os gestores e administradores numa posição passiva, além de deixar implícito que as organizações atuam independentemente dos seres humanos. Se as estratégias são icebergs onde a maior dimensão está submersa, então como as estratégias se formaram? Quem as elaborou?

Buscando responder a esses questionamentos, utiliza-se do que defendem Mintzberg (1978, 1998) e Andrews (2001). Para os autores, estratégia é vista como um padrão ou corrente de decisões importantes. Andrews (2001) conceitua estratégia empresarial como um padrão de decisões em uma empresa que determina e revela seus objetivos, propósitos ou metas, produzindo também as principais políticas e planos.

Mintzberg, em seu texto "A Criação Artesanal da Estratégia", diz que ao perguntar às pessoas qual o significado de estratégia, frequentemente se ouvirá como resposta algo em torno de algum tipo de plano ou um guia claro como referência para comportamentos futuros. Esse é um dos conceitos mais antigos de estratégia dentro da comunidade acadêmica, assim como fora dela.

A estratégia como padrão, conceito utilizado no presente trabalho, é vista como ações no passado que levaram, ou não, ao sucesso da organização (Mintzberg, 1978). Mintzberg (1978) também explica que existem dois tipos de estratégia, as pretendidas e as realizadas. Segundo o autor, as estratégias pretendidas que se tornam realizadas são chamadas de estratégias deliberadas; já as estratégias pretendidas que não se realizam são denominadas de estratégias não realizadas. E as estratégias realizadas que não foram pretendidas são classificadas de estratégias emergentes.

Definido o conceito de estratégia, indica-se que os modos de formação de estratégias surgiram de alguns questionamentos de Mintzberg (1973). Uma dessas questões foi: Como as organizações tomam importantes decisões e como isso se conecta para formar estratégias? Ao buscar a resposta, o autor observou que o processo de formação das estratégias poderia ocorrer de três modos. A tipologia é formada pelo modo empreendedor, modo adaptativo e modo de planejamento. A seguir, comenta-se cada um dos modos.

O modo empreendedor pode ser delineado por algumas características. $\mathrm{O}$ ambiente em que a empresa atua é relativamente maleável como uma força que pode ser confrontada e controlada, comumente, por organizações pequenas ou iniciantes. Nesse modo, as tomadas de decisões estratégicas são impulsionadas pela busca de novas oportunidades, sendo a sua orientação mais ativa do que passiva. Outra característica é que o poder tende a ser centralizado nas mãos do dirigente organizacional. Esse líder é uma pessoa capaz de comprometer-se com o curso das ações, guiando a empresa por meio da sua visão. Ao orientar o empreendimento, o dirigente poderá 
Processo de Formação das Estratégias no Restaurante Leite: Um Estudo entre 1882 e 2009

conduzir a organização levando-a a realizar saltos. Os saltos são mudanças resultantes de um confronto com as incertezas. Finalmente, tem-se que o crescimento é a meta dominante do modo empreendedor.

Já no modo adaptativo, o cenário se caracteriza por um ambiente externo complexo, regido por coalizões de interesses. Há divisão de poder entre os membros organizacionais levando à ausência de metas. Não existe um centro de poder. Com isso, disputam-se os interesses individuais deixando a empresa sem uma orientação definida. Outro aspecto desse modo é o posicionamento reativo. A empresa volta-se muito mais para a resolução de problemas do que para a procura de oportunidades. Ela age passo a passo, negociando, reduzindo o conflito e as incertezas. Por fim, tem-se aqui um dirigente que é flexível e que observa as necessidades do momento.

No modo de planejamento, pode-se também identificar alguns aspectos. O gestor desempenha um papel de analista nesse processo, podendo utilizar técnicas da ciência administrativa e das políticas de análise para delinear as estratégias. A análise sistemática, particularmente o foco nos custos e benefícios, é o condutor desse modo de planejamento. O processo é sempre sistemático e estruturado por meio de uma integração de decisões estratégicas. Por causa disso, o planejamento força a organização a pensar nas estratégias globais e no desenvolvimento, explicitando o senso de direção. Finalmente, ressalta-se que é comum identificar esse modo em organizações de grande porte que se encontrem inseridas em ambientes altamente competitivos.

Os três modos de formação de estratégias apresentados são modelos puros e cada um deles deve se adequar a uma situação, podendo atuar também por combinações. Por isso, verifica-se que poucas empresas os adotam genuinamente (MINTZBERG, 1978, p.50-51). A adoção deles, comumente, reflete as necessidades organizacionais gerando modos híbridos.

No tocante ao processo de formação de estratégias, Quinn (1978, p.7) complementa defendendo que o processo utilizado para chegar à estratégia é tipicamente fragmentado, evolucionário e largamente intuitivo. A fragmentação decorre, muitas vezes, dos desafios que são impostos à organização. Isso leva a atuar com estratégias parcialmente definidas. Já o aspecto evolucionário se caracteriza por compreender o processo ao longo do desenvolvimento da empresa. Finalmente, na intuição, identifica-se o papel humano. Mesmo aceitando que as organizações tenham vida própria, sabe-se que o homem faz parte desse processo. Desse modo, sua percepção e sua compreensão dos fatos direcionam as ações estratégicas.

O autor, então, propõe o modelo do incrementalismo lógico. Para ele, o processo de formação das estratégias desenvolve-se em fases e cada uma sustenta-se nas anteriores. Nelas, a

Revista Ibero-Americana de Estratégia - RIAE, São Paulo, v. 9, n. 2, p. 25-50, mai./ago. 2010. 
Ana Rita de Melo Oliveira, Eduardo de Aquino Lucena, Yákara Vasconcelos Pereira Leite \& Viviane Santos Salazar

organização pode seguir passo a passo, utilizando-se também de mudanças estratégicas por causa da presença de forças dos ambientes interno e externo.

Um ponto a ser ressaltado é que, ao propor esse modelo, o autor levou em consideração evidências teóricas e também empíricas de dez grandes corporações que atuavam em diferentes mercados. Ao longo do desenvolvimento dessas empresas, o pesquisador reconheceu alguns fatores importantes para o processo. O comprometimento dos dirigentes com a diversificação foi um deles. Os gestores saíram em busca de recursos que dessem suporte ao alcance da estratégia principal. Ele percebeu também que as empresas procuravam estar preparadas para mudar oportunistamente. Outro aspecto foi a construção de uma situação de conforto propensa ao risco. Por último, o autor percebeu que, ao realizar uma aquisição, as companhias examinadas trabalhavam o aspecto da cultura organizacional.

O conceito do incrementalismo lógico está ligado também a concisão, proatividade e boa administração, não admitindo o comportamento reativo. Nesse caso, concebe-se o planejamento, sem que seja aquele que enrijece a estratégia, tornando-se o ponto de partida, pois, com o encaminhamento das atividades, oportunidades podem ser identificadas considerando a política e o poder, para que então as estratégias possam emergir.

Hamel e Prahalad (2001, p. 53) seguem por um horizonte semelhante. Para eles, um dos objetivos da intenção estratégica é "proporcionar consistência à ação de curto prazo, ao tempo em que deixa espaço para reinterpretações à medida que novas oportunidades emergem". A intenção estratégica delimita o que se refere ao fim, mas permite a flexibilidade aos meios (p. 54). As estratégias passam a ser adotadas incrementalmente perseguindo o horizonte organizacional, que envolve os membros da própria organização. Assim, o conceito de intenção estratégica está alinhado ao do incrementalismo lógico por considerar que as organizações devam agir proativamente em busca do seu objetivo definido, mas atuando incrementalmente.

Essa ideia de Quinn (1978), do incrementalismo lógico, é uma das mais importantes discussões sobre a perspectiva da formação das estratégias dentro de um processo de aprendizado (MINTZBERG; AHLSTRAND; LAMPEL, 2000). Nesse processo, as estratégias emergem à medida que se tomam decisões. Com isso, as organizações "podem aprender, reconhecendo padrões em seus próprios comportamentos, convertendo assim estratégias emergentes do passado em estratégias deliberadas para o futuro" (p. 150).

Tendo em vista as idiossincrasias do fenômeno analisado, explora-se o modo empreendedor de formação de estratégias.

Revista Ibero-Americana de Estratégia - RIAE, São Paulo, v. 9, n. 2, p. 25-50, mai./ago. 2010. 
Processo de Formação das Estratégias no Restaurante Leite: Um Estudo entre 1882 e 2009

\subsection{ESCOLA EMPREENDEDORA DE FORMAÇÃO DE ESTRATÉGIAS}

Apesar de os conceitos sobre empreendedorismo serem variados e dispersos, de uma forma geral, pode-se dizer que o empreendedorismo está ligado à criação de empresa e à inovação. $\mathrm{O}$ empreendedorismo é definido como o processo pelo qual se faz algo novo (algo criativo) e algo diferente (algo inovador) com a finalidade de gerar riqueza para os indivíduos e agregar valor para a sociedade (FILION, 2004; SHANE; VENKATARAMAN, 2000). O modo empreendedor de formar estratégias caracteriza-se por ser um estilo de administração que impulsiona a empresa em busca de novas oportunidades.

A presença de uma forte liderança marca esta escola de formação de estratégias. A empresa é levada a alcançar seus objetivos por meio de decisões ousadas. Naturalmente, o empreendedor busca ambientes de incertezas, no qual o risco é inerente ao processo decisório como um todo. A percepção do risco que será assumido é um dos fatores que distinguem os empreendedores dos indivíduos comuns. Os riscos são justificados pela expectativa de retornos superiores quando se trata de realizar novas e surpreendentes ações (MCCARTHY, LEAVY, 1999, p. 136). O executivo empreendedor toma para si os riscos assumidos pela empresa, tornando-a flexível (MINTZBERG, 1973, p. 186).

Conforme esta perspectiva teórica, elementos importantes para o sucesso das empresas englobam a sabedoria, a intuição, a experiência e o julgamento dos líderes. O conceito mais relevante e central para esta escola é a visão, pois ela distingue o empreendedor do simples gerente (MINTZBERG; AHLSTRAND; LAMPEL, 2000, p.98). Esta escola é percebida em organizações jovens, pequenas e com uma forte liderança (MINTZBERG, 1973, p. 186).

Empreendedores são os líderes visionários da organização, a quem Rowe (2002, p.11-12) atribui as seguintes características:

\footnotetext{
Líderes visionários são relativamente proativos, moldando ideias em vez de se oporem a elas. Exercem influências de uma maneira que determina a direção que a organização deve tomar. Eles criam imagens e suscitam expectativas, alterando humores e definindo desejos específicos e objetivos. Influenciam o que as pessoas acreditam ser possível, desejável e necessário. [...] esforçam-se para aprimorar escolhas e abordagens novas para problemas antigos. Provocam agitação no ambiente. Trabalham em posição de alto risco e buscam negócios arriscados, especialmente quando as recompensas são altas.
}

Um estudo elaborado por Mintzberg e Waters (1982) apresenta um modelo que exemplifica bem os conceitos da liderança visionária. Uma cadeia de supermercado canadense, a Steinberg, foi investigada pelos autores que destacaram a formação das estratégias ao longo do tempo,

Revista Ibero-Americana de Estratégia - RIAE, São Paulo, v. 9, n. 2, p. 25-50, mai./ago. 2010. 
demonstrando que a empresa inicialmente empreendedora passou por fases de formalização e diversificação. O líder da organização, Sam Steinberg, iniciou suas atividades de rede varejista com uma pequena loja de produtos alimentícios em 1917, na cidade de Montreal. Até o dia da sua morte, em 1978, ele manteve o completo controle formal da empresa, assumindo todas as decisões, inclusive em sua fase de diversificação, na década de 1960.

Com atitudes que demonstravam ser uma "ousadia controlada", ou seja, as ideias eram ousadas, porém a execução destas eram mais cautelosas, o empreendedor "ousou criar uma nova visão, a qual testou antes de dar o salto" (MINTZBERG; AHLSTRAND; LAMPEL, 2000, p.109).

Em adição a noção de ousadia controlada, uma característica do modo empreendedor exaustivamente mencionada pelo próprio fundador da Steinberg - é o profundo conhecimento sobre os negócios que o líder possui. É a intuição que direciona o empreendedor, baseada na sabedoria, detalhada, impregnada, conhecimento pessoal do mundo (MINTZBERG; WATERS, 1982, p. 495).

Este mesmo estudo ainda demonstrou o quanto este conhecimento pode ser efetivo por estar concentrado em um único indivíduo com alto nível de comprometimento e que possuía a visão e a habilidade para mudar de um foco estreito para uma perspectiva ampla. Sob estas condições, tanto tempo dure o negócio simples e concentrado o bastante para ser compreendido por uma única mente, tanto tempo o modo empreendedor se revela bastante eficaz. "Ninguém pode prover tão clara e completa visão de direção, ainda mais permitindo flexibilidade para elaborar e cultivar esta visão" a não ser o empreendedor (p. 496). A visão está articulada na cabeça do empreendedor funcionando como um senso daquilo que a empresa deve fazer (MINTZBERG; AHLSTRAND; LAMPEL, 2000, p.98). A visão tende a ser uma imagem projetada de uma condição a qual se deseja alcançar e não um plano articulado, o que imprime ao processo flexibilidade suficiente para que o empreendedor possa adaptá-la de acordo com sua experiência.

Posto isso, deve-se questionar, como se concebe uma visão? Segundo Mintzberg, Ahlstrand e Lampel (2000, p. 109), os líderes empreendedores buscam captar sinais no ambiente que lhes habilitem a provocar mudanças substanciais na perspectiva estratégica de suas empresas. A aprendizagem do empreendedor o leva a um processo de mudança de visão, pois, a partir da construção de uma nova mentalidade, será construída uma nova visão. Trata-se de transformar modelos mentais, uma mudança de grande magnitude para o indivíduo (p. 110).

Os estudos apresentados acima sobre os empreendedores são classificados por Gartner (1985), considerando os indivíduos que empreendem novos negócios e suas empresas de maneira única. Sendo assim, esse autor propõe um modelo de análise cujo objetivo principal é identificar variáveis que descrevem como cada nova empresa foi criada ou desenvolvida, pois ele considera a

Revista Ibero-Americana de Estratégia - RIAE, São Paulo, v. 9, n. 2, p. 25-50, mai./ago. 2010. 
Processo de Formação das Estratégias no Restaurante Leite: Um Estudo entre 1882 e 2009

abertura de uma empresa um fenômeno complexo e multidimensional. A principal meta da utilização do modelo desse autor é demonstrar importantes contrastes e comparações entre organizações empreendedoras.

O modelo da nova empresa apresentado por Gartner (1985, p. 698) agrupa quatro dimensões que estão inter-relacionadas, são elas:

- Indivíduo - analisado sob aspectos psicológicos referentes a necessidades de realizações, propensão, aceitação de riscos, satisfação no trabalho, experiências anteriores, pais empreendedores, idade e educação;

- Processos - são as ações realizadas para criar uma empresa. Localização da oportunidade de negócio, aglomeração dos recursos, produção dos serviços ou produtos, construção da organização e resposta ao governo e à sociedade;

- Ambiente - variáveis que são relativamente fixas ou impostas. Disponibilidade de capital, presença de empreendedores experientes, acesso a fornecedores, acesso a clientes, influências governamentais, características da população local, barreiras de entrada, rivalidade entre os competidores existentes, pressão dos produtos substitutos, barganha dos compradores e barganha dos fornecedores;

- Organização - variáveis das escolhas estratégicas. Diferenciação, foco, novos produtos e serviços, transferência geográfica, joint ventures e licenciamentos.

A importância das interações dessas variáveis são de relevância elucidativa para o entendimento do surgimento das novas empresas.

\section{PROCEDIMENTOS METODOLÓGICOS}

A pesquisa qualitativa foi escolhida neste trabalho como abordagem metodológica por se tratar de um método que valoriza os proponentes descritivos, facilitando o alcance do objetivo principal deste trabalho: entender, através de uma perspectiva histórica, como tem se dado o processo de formação das estratégias do restaurante Leite de 1882 a 2009; e por privilegiar a compreensão dos comportamentos a partir da perspectiva dos sujeitos da investigação (Godoy, 1995). Nesse sentido, o modelo utilizado neste trabalho foi o estudo de caso, pela sua característica fundamental que, segundo Godoy (1995), é a análise intensiva de uma unidade social.

Revista Ibero-Americana de Estratégia - RIAE, São Paulo, v. 9, n. 2, p. 25-50, mai./ago. 2010. 
Ana Rita de Melo Oliveira, Eduardo de Aquino Lucena, Yákara Vasconcelos Pereira Leite \& Viviane Santos Salazar

Considerando as premissas da pesquisa qualitativa e a natureza do fenômeno, utilizou-se para esta pesquisa a estratégia de estudo de caso (MERRIAM, 1998), por ela contribuir para a compreensão dos fenômenos individuais e organizacionais, principalmente quando os objetos são complexos e contemporâneos (YIN, 2002). Outro aspecto foi que não se objetivou generalizar estatisticamente os resultados, mas procurou-se contribuir para um melhor entendimento do que está sendo investigado (EISENHARDT, 1995; MERRIAM, 1998; STAKE, 1995).

O método pareceu ser apropriado para o fenômeno em investigação. Acredita-se, ainda, que o estudo de caso esteja contribuindo para o desenvolvimento das pesquisas na área da administração estratégica na indústria da hospitalidade que engloba restaurantes, principalmente por permitir a análise aprofundada (OKUMUS; HEMMINGTON, 1998; OLSEN; ROPER, 1998).

Stake (1995) explica também que é caracterizada como estudo de caso a investigação que se concentra na compreensão de um caso particular. Apoiada nesse pensamento, buscou-se estudar o processo de formação das estratégias no Restaurante Leite. Com isso, atingiu-se a especificidade por selecionar um fenômeno dentro de uma organização particular.

Diante do problema desta pesquisa, a análise foi realizada em retrospectiva. Ela tornou-se fundamental para o entendimento de eventos históricos que acessam o contexto organizacional considerando as interpretações dos respondentes (GLICK et al, 1995). A utilização dessa análise vem se apresentando eficaz nos trabalhos que investigam o processo estratégico (MINTZBERG, 1978; MINTZBERG; WATERS, 1982; MINTZBERG; MCHUGH, 1985; PETTIGREW, 1987). Assim, a estratégia metodológica desta pesquisa pode ser caracterizada como um estudo de caso qualitativo histórico de cunho descritivo (MERRIAM, 1998).

No estudo de caso, o pesquisador geralmente utiliza uma variedade de dados coletados em diferentes momentos através de variadas fontes de informação, tendo como técnicas fundamentais de pesquisa: a observação e a entrevista (GODOY, 1995). Para o vigente trabalho, foram selecionadas as técnicas de entrevista semiestruturada e análise de documentos.

As entrevistas ocorreram no Restaurante Leite, foram transcritas e analisadas. Ao todo foram entrevistadas seis pessoas que podem ser visualizadas no quadro 1 a seguir com a indicação de sua ligação com a empresa.

Revista Ibero-Americana de Estratégia - RIAE, São Paulo, v. 9, n. 2, p. 25-50, mai./ago. 2010. 
Processo de Formação das Estratégias no Restaurante Leite: Um Estudo entre 1882 e 2009

\begin{tabular}{|l|l|}
\hline \multicolumn{1}{|c|}{ NOME } & \multicolumn{1}{c|}{ LIGAÇÃO COM A EMPRESA } \\
\hline Armênio Diogo & Proprietário desde 1955 \\
\hline Manoel Silva & Gard Manger desde 1974 \\
\hline Bigode & Chef desde 1992 \\
\hline Orlando & Maître desde 1992 \\
\hline Isabel Sousa & Bisneta de Manoel Leite \\
\hline Xavier da Silva & Garçon desde 1973 \\
\hline
\end{tabular}

Quadro 1 - Apresentação dos entrevistados.

Fonte: Elaborado autores.

$\mathrm{Na}$ análise documental foram utilizadas a pesquisa bibliográfica e a pesquisa documental da história do restaurante em que Ruiz (1996) diferencia: pesquisa bibliográfica é desenvolvida a partir de material já elaborado (livros, artigos científicos, etc.) e pesquisa documental é o material que ainda não recebeu tratamento analítico ou que pode ser re-elaborado (documentação da empresa em estudo).

Como exemplo, neste trabalho, pode ser citado o livro $O$ Leite ao sabor do tempo escrito pela jornalista Goretti Soares no qual é contada toda a história do restaurante. Esse livro foi utilizado principalmente na elaboração da primeira, segunda e terceira fases do restaurante descritas no presente trabalho.

Para a análise de dados, os resultados foram agrupados em categorias, ou melhor, fases, mais precisamente em anos, o que facilitou a análise das estratégias desenvolvidas ao longo do tempo (Taylor \& Bogdan, 1984). Salienta-se também que a análise foi em retrospectiva por compreender o período de 1882 a 2009.

\section{RESULTADOS}

O restaurante Leite é um dos restaurante mais antigos em funcionamento no Brasil com 124 anos de existência. A casa já foi eleita inúmeras vezes a melhor da capital pernambucana pelo júri da revista VEJA Recife, além de diversas honrarias de revistas, jornais e do governo do Estado. O Leite situa-se na Praça Joaquim Nabuco no centro comercial da cidade de Recife. O restaurante funciona de domingo a sexta-feira para almoço e dispõe de um bar, pianista, manobrista e segurança, possui 150 lugares, uma brigada composta de 33 funcionários e um cardápio com o

Revista Ibero-Americana de Estratégia - RIAE, São Paulo, v. 9, n. 2, p. 25-50, mai./ago. 2010. 
melhor da gastronomia internacional, além de alguns pratos regionais. A cozinha recebe especial atenção de dois cozinheiros habilitados ao cardápio, já conhecido e apreciado pela clientela. Ao público, é destinada uma equipe com: um maître, dez garçons, dois cummins (ajudantes de garçons), um barman, um caixa, dois manobristas e um segurança. Seu público-alvo é a classe "A". Além de oferecer almoços diariamente, o restaurante também trabalha com eventos fechados em seu próprio ambiente, não sendo este um serviço rotineiro.

Após a breve apresentação da organização, passa-se para a descrição das fases vivenciadas pela empresa, nelas são demonstrados as principais estratégias adotadas, os modos de formação das estratégias e a classificação como deliberadas e/ou emergentes (ver quadro 2).

\begin{tabular}{|c|c|c|c|}
\hline FASE & AÇÕES ESTRATÉGICAS & $\begin{array}{l}\text { MODELO DE FORMAÇÃO } \\
\text { DAS ESTRATÉGIAS }\end{array}$ & $\begin{array}{l}\text { TIPOS DE } \\
\text { ESTRATÉGIAS }\end{array}$ \\
\hline $\begin{array}{l}\left.1^{\mathrm{a}}\right) 1882- \\
\text { Mudança de } \\
\text { endereço } \\
\text { (Abertura do } \\
\text { negócio) }\end{array}$ & $\begin{array}{l}\text { Abertura do restaurante com nível de } \\
\text { sofisticação simples. Serviço de jantar. }\end{array}$ & Empreendedor & Deliberada \\
\hline $\begin{array}{l}2^{a} \text { ) Novo } \\
\text { endereço }-1940 \\
\text { (Demanda pelo } \\
\text { luxo) }\end{array}$ & $\begin{array}{l}\text { Mudança de endereço; sofisticação do } \\
\text { estabelecimento; abertura para almoço } \\
\text { e jantar e estratégia de continuidade } \\
\text { quanto ao nível de sofisticação do } \\
\text { estabelecimento. }\end{array}$ & Empreendedor & Deliberada \\
\hline $\begin{array}{l}\left.3^{\text {a }}\right) \text { 1941-1945 } \\
\left(2^{\mathrm{a}} \text {.Guerra }\right. \\
\text { Mundial }) \\
\end{array}$ & $\begin{array}{c}\text { Enfoque nos militares; fornecimento de } \\
\text { lanches para companhias aéreas } \\
\text { (ampliação dos serviços) }\end{array}$ & Empreendedor & Emergente \\
\hline $\begin{array}{l}\left.4^{\mathrm{a}}\right) \text { 1946-1949 }(\mathrm{O} \\
\text { Leite na } \\
\text { modernidade })\end{array}$ & $\begin{array}{l}\text { Modernização da estrutura física; } \\
\text { abertura de uma boate; Mudança no } \\
\text { perfil do cardápio. }\end{array}$ & Empreendedor & Deliberada \\
\hline $\begin{array}{l}\left.5^{a}\right) 1950-1955 \\
\text { (O Leite vai à } \\
\text { falência) }\end{array}$ & $\begin{array}{l}\text { Distanciamento da estratégia de } \\
\text { diferenciação e venda do restaurante. }\end{array}$ & Empreendedor & $\begin{array}{l}\text { Deliberada e } \\
\text { emergente }\end{array}$ \\
\hline $\begin{array}{l}6^{\text {a) }} 1956-1979 \\
\text { (O retorno da } \\
\text { classe "A") }\end{array}$ & $\begin{array}{l}\text { Modernização da estrutura física; } \\
\text { eliminaçãa da boate; Estratégia de } \\
\text { diferenciação até 1965; Ampliação dos } \\
\text { serviços (eventos externos); eliminação } \\
\text { dos jantares em 1970. }\end{array}$ & Empreendedor & $\begin{array}{l}\text { Deliberada e } \\
\text { emergente }\end{array}$ \\
\hline $\begin{array}{l}7^{\text {a) }} \text { 1980-1990 } \\
\text { (Período } \\
\text { decadente) }\end{array}$ & $\begin{array}{l}\text { Compra de mercadoria em grande } \\
\text { quantidade; distanciamento da } \\
\text { estratégia de diferenciação. }\end{array}$ & Empreendedor & Emergente \\
\hline $\begin{array}{c}\left.8^{a}\right) 1991-2006 \\
\text { (Investimento em } \\
\text { qualidade) }\end{array}$ & $\begin{array}{l}\text { Modernização da estrutura; foco na } \\
\text { estratégia de diferenciação; volta dos } \\
\text { jantares e posterior eliminação; } \\
\text { mudança no perfil do cardápio. }\end{array}$ & Empreendedor & Deliberada \\
\hline
\end{tabular}

Quadro 2 - Processo de formação das estratégias do Restaurante Leite.

Fonte: Dados coletados.

A seguir as fases serão descritas.

Revista Ibero-Americana de Estratégia - RIAE, São Paulo, v. 9, n. 2, p. 25-50, mai./ago. 2010. 
Processo de Formação das Estratégias no Restaurante Leite: Um Estudo entre 1882 e 2009

\subsection{PRIMEIRA FASE: 1882 - ANO DA MUDANÇA DE ENDEREÇO (ABERTURA DO NEGÓCIO)}

Em 1882, o português Manoel Leite, recém-chegado ao Brasil, inaugura um pequeno quiosque denominado Restaurante Manoel Leite. Sua localização, na época, era na Rua do Sol, próximo à ponte Boa Vista e ao Porto das Canoas, bem em frente aos trilhos do bonde. O Leite inicia suas atividades com um ambiente simples e sem luxo. Entretanto, segundo Soares (2000), o restaurante oferecia atendimento e comida de qualidade e, ao utilizar-se da rede de relacionamento que tinha formado ao frequentar o Clube Internacional, o senhor Manoel Leite transformou o restaurante em um dos pontos badalados da cidade.

Diante disso, ao analisar os dados, percebeu-se que as estratégias desse período são deliberadas (Mintzberg, 1978, 1998; Mintzberg \& Waters, 1982; Mintzberg \& Mchugh, 1985; Mintzberg \& Waters, 1985; Mintzberg et al., 2000), visto que para abrir o negócio precisou escolher o local onde funcionaria o restaurante, definir a estrutura física, o tipo de serviço a oferecer, o perfil do cardápio e dos clientes.

\subsection{SEGUNDA FASE: ANO DA MUDANÇA DE ENDEREÇO - 1936 (DEMANDA POR LUXO)}

De acordo com Soares (2000), com o tempo, o restaurante prosperou, e os próprios fregueses começaram a exigir um local maior e mais adequado. Nessa fase, ele vislumbrou a oportunidade de promover uma grande mudança: transformar o restaurante no mais luxuoso do Estado. Transferiu o estabelecimento para outro endereço, reformou e decorou o ambiente, passou a servir com materiais e utensílios importados, tais como: louça inglesa, taças e copos do mais fino cristal bacará francês, os talhares de prata Christoffle e tolhas de damasco francês. Ampliou os serviços, passando a oferecer também almoço ao som de piano.

De quiosque passou à restaurante fino, tornando-se o único estabelecimento gastronômico da cidade recifense. A clientela era composta por senhores de engenho, políticos e personalidades da época, que, de acordo com Soares (2000), se vestiam rigorosamente de paletó e gravata e as senhoras trajavam a mais requintada moda de Londres.

Entretanto, na primeira década do século passado, o Restaurante Manoel Leite passa por uma grave crise financeira. Isabel Sousa, bisneta de Manoel Leite, explicou que a causa da crise teve origem em Portugal, onde morava a família do senhor Manoel, por conta da crise econômica

Revista Ibero-Americana de Estratégia - RIAE, São Paulo, v. 9, n. 2, p. 25-50, mai./ago. 2010. 
que Portugal passava à época. Diante da situação da família, o senhor Leite passou a enviar-lhes dinheiro, desfalcando o caixa do restaurante, levando-o a decidir, em 1910, a vender o restaurante ao senhor Bernardo Wenceslau, que era o seu gerente, e voltar para Portugal. O segundo proprietário procurou dar continuidade ao trabalho que vinha sendo feito pelo proprietário fundador, preservando o perfil do restaurante.

\subsection{TERCEIRA FASE: $1937-1945$ (FORNECIMENTO DE LANCHES PARA COMPANHIAS AÉREAS)}

A partir de 1937, o Brasil passou por uma grande transformação, com a instalação da ditadura Vargas, o desenvolvimento da indústria fabril, o crescimento do êxodo rural, a proliferação de favelas nos centros urbanos, o surgimento da mão de obra feminina, culminando com a $2^{\mathrm{a}}$. Guerra Mundial. Durante o período de 1939-1945, a cidade de Recife foi o quartel-general das forças do Atlântico Sul.

De acordo com Soares (2000), foi uma época muito boa para o restaurante Manoel Leite, pois a casa recebia uma grande quantidade de militares norte-americanos no almoço e no jantar. Além disso, o restaurante foi requisitado a fornecer lanches para as companhias aéreas que faziam escalas no Estado: Panair do Brasil, Aerovias Brasil, Cruzeiro do Sul e a Navegação Aérea Brasileira. Entretanto, com o retorno dos militares ao seu país de origem, mais a crise econômica que se instalava causada pela entrada de empresas multinacionais no Brasil e o declínio das exportações, o senhor Bernardo, segundo Armênio Diogo, vislumbrou uma possível crise financeira para o seu restaurante e, com a saúde já debilitada, decidiu vendê-lo.

A terceira fase (1941-1945) foi marcada pela estratégia de continuidade, uma vez que o segundo proprietário, Bernardo Wenceslau, deu seguimento aos trabalhos desenvolvidos pelo administrador anterior. Entretanto, observou-se o surgimento de uma estratégia emergente quando o restaurante passa a receber solicitações para fornecer lanches às companhias aéreas que faziam escala no Estado.

\subsection{QUARTA FASE: 1946-1949 (O LEITE NA MODERNIDADE)}

No pós-guerra, o Brasil vivencia uma crise econômica. Nessa época o restaurante Leite volta a ser vendido, dessa vez para um grupo de personalidades da elite pernambucana que decide criar uma sociedade anônima com o senhor João Lacerda à frente do restaurante.

Revista Ibero-Americana de Estratégia - RIAE, São Paulo, v. 9, n. 2, p. 25-50, mai./ago. 2010. 
Processo de Formação das Estratégias no Restaurante Leite: Um Estudo entre 1882 e 2009

O então presidente Eurico Gaspar Dutra abre as portas para a importação e a concorrência compromete a produção industrial interna. Além disso, a instalação de multinacionais, cujos lucros eram remetidos ao exterior, só fazia prejudicar o desenvolvimento do país. A partir da década de 1950, o Brasil entra para o seu melhor período de crescimento. Getúlio Vargas cria o Banco Nacional de Desenvolvimento Econômico e Social (BNDES), a Eletrobrás e a Petrobrás.

Nos primeiros anos da administração de João Lacerda, o Leite passou por uma completa reforma que o tornou mais moderno e amplo, expandiu os serviços e inaugurou uma boate em suas dependências. $\mathrm{O}$ novo restaurante Leite passa a viver mais intensamente à noite, pois o seu novo administrador, João Lacerda, segundo Armênio Diogo, era considerado grande boêmio, adorava fazer grandes festas e chegou a receber convidados ilustres, segundo Soares (2000), como a Duquesa de La Rochefoucauld e o jornalista Assis Chateaubriand.

Outra mudança global verifica-se na estrutura do cardápio que inicia a adoção de pratos da culinária nordestina. Nessa fase, a valorização do produto nacional é intensa em virtude da influência do desenvolvimento da economia e do enfoque do governo Getúlio Vargas.

Desse modo, com o senhor João Lacerda à frente dos negócios, foram adotadas estratégias deliberadas no que se refere à reforma do restaurante; à expansão dos serviços com a inauguração de uma boate nas dependências do estabelecimento e à mudança no perfil do cardápio.

\subsection{QUINTA FASE: 1950 - 1955 (O LEITE VAI À FALÊNCIA)}

O despojamento festivo do boêmio acabou prejudicando o administrador e, em 1955, o Restaurante Leite veio a falir, apesar da fase de crescimento do Brasil no período de 1950 a 1980. A sociedade anônima proprietária do Restaurante Leite estava com sérios problemas no mercado tinha vários títulos protestados e devia ao governo uma importância muito alta em impostos. A crise afetava o funcionamento do restaurante, o atendimento já não era o mesmo e a clientela diminuía (Soares, 2000).

Levando em consideração que a estratégia é consistência no comportamento (Mintzberg, 2001), e que durante a administração de João Lacerda o nível de sofisticação do restaurante diminuiu bruscamente, observa-se o surgimento de uma estratégia emergente - distanciamento da estratégia de diferenciação. A estratégia original buscava atrair o público-alvo por meio da elevação da qualidade dos serviços. Fato que se mostrou em queda nessa fase.

Revista Ibero-Americana de Estratégia - RIAE, São Paulo, v. 9, n. 2, p. 25-50, mai./ago. 2010. 
Ana Rita de Melo Oliveira, Eduardo de Aquino Lucena, Yákara Vasconcelos Pereira Leite \& Viviane Santos Salazar

\subsection{SEXTA FASE: 1956 - 1980 (O RETORNO DA CLIENTELA “A”)}

Segundo Alves (2005), durante os anos de 1950 a1980 a economia brasileira cresceu, em números redondos, a uma média de $7 \%$, enquanto a população cresceu $2,8 \%$ ao ano. A renda per capita aumentou 4,2\% ao ano. Esses trinta anos marcaram o melhor período de crescimento de toda a história brasileira. O Brasil partiu de uma base muito baixa e contou com uma grande transformação em decorrência da passagem de uma sociedade rural e agrária para uma sociedade urbana e industrial.

Em maio de 1956, os irmãos Dias assumiram o restaurante. A sociedade era formada pelos irmãos Amadeu Dias, Luiz Dias e Armênio Diogo, além do amigo Hugo Laprovítera, que ficou pouco tempo na sociedade. Antes de abrir o restaurante ao público, os novos donos decidiram fazer uma reforma no ambiente.

Segundo Armênio Diogo, a inauguração foi um sucesso: “o Leite voltou ao auge. Nós entramos aqui a trabalhar, com sete meses o Leite começou a encher, pá, pá, pá". A clientela do Leite volta a ser composta por usineiros, políticos, personalidades e famílias tradicionais.

Outro serviço significativo do Leite eram os eventos externos. Essa fase é marcada por diferentes ações realizadas pelos irmãos Dias. Essas atuações foram iniciadas com a reforma do ambiente do restaurante, fechando a boate; diversificando a oferta de serviços - passaram a oferecer almoço e jantar ao som de piano, jantares dançantes nas sextas-feiras e nos sábados. Essas ações se caracterizam como estratégias deliberadas. Foi durante a sexta fase que o Leite intensificou o trabalho com organização de eventos externos. Sendo esta estratégia caracterizada como emergente pelo fato de não ter sido uma decisão da administração, mas uma demanda do mercado que aumentou de forma progressiva.

\subsection{SÉTIMA FASE: 1980 - 1990 (INFLAÇÃO GALOPANTE)}

A década de 1980 é marcada pela queda no crescimento da economia brasileira, por níveis muito altos de inflação, pela dívida externa bilionária e pela transição da ditadura para as eleições diretas.

Segundo Manoel Silva, o período inflacionário foi marcado por um volume gigantesco de compra de mercadoria. "Era $1200 \mathrm{~kg}$ de arroz, 200 latões de óleo, 100 garrafas de vinho branco. Tudo pra vencer a inflação." O restaurante conseguiu sobreviver à turbulência do ambiente externo (segmento econômico), para tanto, Armênio Diogo explica que todos os dias fazia correções no cardápio quanto ao valor.

Revista Ibero-Americana de Estratégia - RIAE, São Paulo, v. 9, n. 2, p. 25-50, mai./ago. 2010. 
Processo de Formação das Estratégias no Restaurante Leite: Um Estudo entre 1882 e 2009

A década de 1980 também é lembrada como o início do declínio dos eventos externos que o restaurante fazia. De acordo com Orlando, o surgimento da concorrência, tais como: Cristina Manzi, Rose Beltrão, Blue Angel, ocasionou a diminuição das solicitações, até porque não era o produto principal do restaurante. Observa-se então que, durante essa fase, as ações caracterizam-se como estratégia emergente.

\subsection{OITAVA FASE: $1991-2009$ (NOVAS DIRETRIZES)}

A década de noventa é marcada pela abertura do mercado brasileiro à importação e exportação de bens e produtos no governo de Collor e pelo surgimento do plano Real. Com isso, o Brasil adquire certa estabilidade econômica e começa a dar os passos para o desenvolvimento tecnológico. Nessa última fase do restaurante Leite, o que mais preocupa é a violência no centro da cidade e consequente degradação do ambiente ao redor do Leite com prostitutas, mendigos e "trombadinhas".

Então, em 1991, Orlando explica que o restaurante fechou por oito meses para reforma. Com a reforma, os sócios Amadeu e Armênio decidem abrir o restaurante para jantar, entretanto, seis meses depois, voltaram a fechar à noite e só abrir pela manhã, pois quase não havia movimentação de clientes. Houve uma mudança no nível do restaurante. Em 1994, morre o senhor Amadeu Dias, pessoa responsável pela administração direta do restaurante. Com a morte do irmão, Armênio Diogo chama um sobrinho para administrar o restaurante, pois Armênio andava muito ocupado com a administração da casa de câmbio.

Entretanto, o gerenciamento do sobrinho quase leva o restaurante à falência, segundo o senhor Armênio. Foi aí, então, que Armênio Diogo reassume o restaurante em 1995. Armênio Diogo sempre foi um administrador visionário. Por meio de seus conhecimentos gastronômicos adquiridos quando ainda trabalhava na melhor pastelaria de Portugal, Armênio abriu a padaria Aparecida, em Boa Viagem, a pastelaria Arcádia, na rua da Aurora, comprou a Casa dos Frios e o restaurante Leite.

Nesse período observa-se que o restaurante é gerido principalmente por Armênio Diogo. Sendo o restaurante gerido por líderes empreendedores em que a estratégia não é um plano e, sim, uma visão, ou seja, uma representação mental da estratégia, criada ou, ao menos, expressa na cabeça do líder e construída a partir de experiências passadas e pelo fato do restaurante permanecer no estágio empreendedor (Mintzberg \& Water, 1982), conclui-se que o modelo de formação de estratégia utilizado ao longo do tempo foi o empreendedor (Mintzberg et al., 2000).

Revista Ibero-Americana de Estratégia - RIAE, São Paulo, v. 9, n. 2, p. 25-50, mai./ago. 2010. 
Ana Rita de Melo Oliveira, Eduardo de Aquino Lucena, Yákara Vasconcelos Pereira Leite \& Viviane Santos Salazar

\section{CONSIDERAÇÕES FINAIS}

Um das principais questões estratégicas é a constante adaptação das empresas às mudanças ambientais. Para isso, a alta administração lança mão dos conhecimentos de estratégia que são descrioas na maior parte dos livros-texto, como planos da alta administração para garantir resultados consistentes com as missões e objetivos da organização (MINTZBERG, AHLSTRAND, LAMPEL, 2000).

Apesar da popularidade do Planejamento Estratégico como a melhor forma de criar e implementar estratégias, Mintzberg (1998) argumenta que é um equívoco pensar que as estratégias só se formam através de procedimentos deliberados, visto que as estratégias também surgem de maneira não intencional. Assim, entender como foi o processo de formação das estratégias do restaurante mais antigo do país, o Leite, pode elucidar importantes questões para a indústria da alimentação fora do lar em franco desenvolvimento no Estado de Pernambuco e no país.

Durante a realização deste estudo constatou-se que o processo de formação de estratégias do restaurante Leite ao longo dos anos se processou predominantemente no modo empreendedor (Mintzberg, 1973), utilizando-se ora de estratégias deliberadas, ora de emergentes (Mintzberg, 1978, 1998; Mintzberg \& Waters, 1982; Mintzberg \& Mchugh, 1985; Mintzberg \& Waters, 1985; Mintzberg et al., 2000). O modo empreendedor presente no processo de formação das estratégias do Restaurante Leite é explicado em razão da própria estrutura simples da empresa, a qual é sensível às diretivas do administrador da ocasião. Acredita-se também que por não ter tido uma administração de longo prazo, sempre mudando de proprietário, o estabelecimento permaneceu até os dias atuais com a configuração empreendedora.

O modelo empreendedor oferece certa flexibilidade na adaptação das estratégias ao contexto dos ambientes interno e externo à empresa, sem implicação com procedimentos burocráticos (Mintzberg, 1982), concedendo autonomia ao administrador para decidir de acordo com a sua vontade, como foi constatado diversas vezes durante todo o período como, por exemplo, abrir ou não o restaurante à noite, fechar ou não a boate, ampliar os serviços, mudar o perfil do cardápio, mudar de endereço, sofisticar o estabelecimento.

Apesar de não ser o foco principal deste trabalho, ao longo do processo de formação das estratégias do Restaurante Leite, pode-se observar algumas mudanças estratégicas a fim de adequar os serviços aos objetivos dos administradores:

Revista Ibero-Americana de Estratégia - RIAE, São Paulo, v. 9, n. 2, p. 25-50, mai./ago. 2010. 
Processo de Formação das Estratégias no Restaurante Leite: Um Estudo entre 1882 e 2009

- Mudança no nível de sofisticação do restaurante quando da mudança de endereço no início do século passado, para atender a demanda da clientela da alta sociedade recifense - composta de senhores de engenho, políticos e personalidades da época;

- Re-abertura (Após uma reforma, reabre utilizando a estratégia de diferenciação e enfoque - 1957). Passa a oferecer os serviços de jantar e almoço ao som de piano, e jantares dançantes nas sextas e nos sábados, além de eventos externos - com serviços de buffet. A clientela volta a ser composta de personalidades da alta sociedade, como: usineiros, políticos e famílias tradicionais.

Modernização do restaurante com expansão dos serviços - inauguração de boate, no início da década de 1950 para adaptar-se às tendências do ambiente externo, além de enfatizar a vida noturna, promovendo grandes festas para receber convidados ilustres, como a Duquesa de La Rochefoucauld, em razão do perfil boêmio do administrador. Verificou-se a influência da valorização do nacional pela sociedade da época na transformação do perfil do cardápio que passou a apreciar pratos regionais;

- Inserção do restaurante na era da tecnologia em 1995 - instalando circuito fechado de televisão - CFTV nos seus ambientes, e computadores para tornar os serviços ágeis e eficientes nas áreas: fiscal, financeira e estoque.

Finalmente, pretendeu-se contribuir no aprofundamento do conhecimento da Administração Estratégica acerca da formação de estratégias. Além disso, buscou-se apresentar aos praticantes da gestão da hospitalidade a descrição das possíveis estratégias e o seu modo de formação para que um empreendimento possa ter uma trajetória secular de desenvolvimento empresarial.

\section{REFERÊNCIAS}

Abrasel. Guia gastronômico Abrasel 2003. Recuperado em 05 de julho, 2005 de http://www.abraselpe.org.br/guia.asp

Alves, J. E. D. (2005). O Bônus Demográfico e o Crescimento Econômico no Brasil. Rio de Janeiro: IBGE . Recuperado em 23 de setembro, 2006 de http://www.ie.ufrj.br/aparte

Revista Ibero-Americana de Estratégia - RIAE, São Paulo, v. 9, n. 2, p. 25-50, mai./ago. 2010. 
Andrews, Kenneth R. O conceito de estratégia empresarial. (2001). In: Mintzberg, H.; Quinn, J. B. O processo da estratégia. 3. ed. Porto Alegre: Bookman, p. 58-64.

Ansoff, H. Igor. (1973). Toward a strategic theory of the firm. In: Britain: Penguin Books, p. 11-40.

Business strategy. Great

Chandler, Alfred. (1998). Introdução a strategy and struture. In: Ensaios para uma teoria histórica da grande empresa. Rio de Janeiro: Fundação Getúlio Vargas. p. 121-140.

De Wit, Bob; Meyer, Ron. Introduction. In: Strategy: process, content, context. 3. ed. London: Thomson, 2004. Cap. 3, p. 105-162.

Eisenhardt, Kathleen M. (1995). Building theories from case study research. In: HUBER, George P.; VAN DE VEN, Andrew H. (Org.). Longitudinal field research methods: studing processes of organizational change. Thousand Oaks: Sage, p. 65-90.

Filion, L. J. (1999). Empreendedorismo: empreendedores e proprietários-gerentes de pequenos negócios. Revista de Administração, São Paulo, v. 34, n.2, p.05-28, Abr/Jun.

Gartner, W. B. (1985). A conceptual framework for describing the phenomenon of new venture creation. Academy of Management Review, v. 10, n. 4, Oct.

Grant, Robert M. (1995). Contemporary strategy analysis: concepts, techniques, applications. Blacwell Business. p. 4-28.

Henderson, Bruce D. (1998). As origens da estratégia. In: MONTGOMERY, V.; PORTER, M. Estratégia: a busca da vantagem competitiva. 2. ed. Rio de Janeiro: Campus. p. 3-9.

Hitt, M. A., Ireland, R. D. \& Hoskisson, R. E. (2002). Administração estratégica. São Paulo: Thompson.

Godoy, A. S. (1995, mai/jun). Pesquisa qualitativa: tipos fundamentais. Revista de Administração de Empresas, 35(3), 20-29.

Idenburg, P. J. (1993). Four Styles of Strategy Development. Long Range Planning, 26(6), 133-134. http://dx.doi.org/10.1016/0024-6301(93)90215-2

Mahier, S. A evolução desta atividade está diretamente ligada à participação da mulher no mercado de trabalho. DN Online. Recuperado em 04 de maio, 2006 de http://culinaria.dnonline.com.br/noticias/entrevista.php

Mccarthy, B.; Leavy, B. (1999). The entrepreneur, risk-perception and change over time: a typology approach. IBAR, v. 20, n. 1, p.126-140. 
Processo de Formação das Estratégias no Restaurante Leite: Um Estudo entre 1882 e 2009

Merriam, Sharan B. Qualitative research and case study applications in education. San Francisco: Jossey-Bass, 1998.

Mintzberg, H. (1973, Winter). Strategy-making in three modes. California Management Review, 16(2), 44-53.

Mintzberg, H. (1978, mai.). Patterns in Strategy Formation. The Institute of Management Science, 24(9), 934, 935.

Mintzberg, H. \& Waters, J. A. (1982). Tracking Strategy in an Entrepreneurial Firm. Academy of Management Journal, 25(3), 465-499.

http://dx.doi.org/10.2307/256075

Mintzberg, H. \& Mchugh, A. (1985, jun.). Strategy formation in an adhocracy. Administrative Science Quarterly, 30, 160-197.

http://dx.doi.org/10.2307/2393104

Mintzberg, H. (1994, jan.-fev.). The fall and Rise of Strategic Planning. Harvard Business Review, 72(1), 107-114.

Mintzberg, H. (1998). A Criação Artesanal da Estratégia. In C. Montgomery \& M. Porter, Estratégia: a busca da vantagem competitiva (2a ed). (pp. 420-421). Rio de Janeiro: Campus.

Mintzberg, H., Ahlstrand, B. \& Lampel, J. (2000). Safári de Estratégia. Porto Alegre: Bookman.

Mintzberg, H. (2001). Os 5 Ps da Estratégia. In H. Mintzberg \& J. B. Quinn (Orgs.), O processo da estratégia (pp. 97-144). Porto Alegre: Bookman.

Netmba. Frederick Taylor and Scientific Management. Recuperado em 4 de julho, 2006 de http://www.netmba.com/mgmt/scientific/

Ohmae, Kenichi. Voltando à estratégia. (1998). In: MONTGOMERY, V.; PORTER, M. Estratégia: a busca da vantagem competitiva. 2. ed. Rio de Janeiro: Campus. p. 67-81.

Okumus, Fevzi; Hemmington, Nigel. (1998). Management of the change process in hotel companies: an investigation at unit level. Hospitality Management, v. 17, p. 363-374.

http://dx.doi.org/10.1016/S0278-4319(98)00027-9

Olsen, Michael D.; ROPER, Angela. (1998). Research in strategic management in the hospitality industry. Hospitality Management, v. 17, p. 111-124.

http://dx.doi.org/10.1016/S0278-4319(98)00012-7

Revista Ibero-Americana de Estratégia - RIAE, São Paulo, v. 9, n. 2, p. 25-50, mai./ago. 2010. 
Ana Rita de Melo Oliveira, Eduardo de Aquino Lucena, Yákara Vasconcelos Pereira Leite \& Viviane Santos Salazar

Pettigrew, Andrew M. (1987). Context and action in transformation of the firm. Journal of Management Studies, v. 24, n. 6, p. 649-670, Nov. 1987. http://dx.doi.org/10.1111/j.1467-6486.1987.tb00467.x

Porter, Michael. (1986). Estratégia competitiva: técnicas para análise de indústrias e da concorrência. Rio de Janeiro: Campus.

Porter, Michael. (1999). O que é estratégia? In: . Competição estratégicas competitivas essenciais. Rio de Janeiro: Campus. p 46-82.

Quinn, J. B. (1978, out.). Strategic Change: Logical Incrementalism. Sloan Management Review, 20(1), 7-21.

Rowe, W. Glenn. Liderança estratégica e criação de valor. (2002). RAE - Revista de Administração de Empresas, v. 42, n.1, p. 7-19, jan./mar.

Shane, S.; Venkataraman, S. (2000). The promise of entrepreneurship as a field of research. Academy of Management Review, v.25,n.1, p. 217-226, jan.

http://dx.doi.org/10.2307/259271

http://dx.doi.org/10.5465/AMR.2000.2791611

Soares, G. (2000). O Leite ao sabor do tempo. Recife: Melhoramentos.

Stake, Robert E. (1995). The case of case study research. Thousand Oaks: Sage Publications, p. 112.

Taylor, S. J. \& Bogdan, R. (1984). Introduction to qualitative research methods: the search for meanings (2a ed). John Wiley \& Sons.

Yin, Robert K. (2001). Estudo de Caso: planejamento e métodos. 2. ed. Porto Alegre: Brookman.

Revista Ibero-Americana de Estratégia - RIAE, São Paulo, v. 9, n. 2, p. 25-50, mai./ago. 2010. 
Recebido: $25 / 05 / 2010$

Aprovado: 12/09/2010

Revista Ibero-Americana de Estratégia - RIAE, São Paulo, v. 9, n. 2, p. 25-50, mai./ago. 2010. 